\title{
OBTENÇÃo DE BIO-ÓLEO A PARTIR DA CASCA DE ARROZ
}

\author{
Camila Oliveira GUIMARÃES ${ }^{1}$ \\ Gabriel Renoult MENDONÇA ${ }^{1}$ \\ Maikel Laurence MALONCY ${ }^{2}$ \\ Marcelo da Silva BATISTA ${ }^{3}$
}

\author{
1. Discente, Universidade Federal de São João Del Rei, Curso de Graduação em Engenharia Química; \\ ${ }^{2}$. Docente, The Hague University of Applied Sciences, Process and Food Technology, The Netherlands; .1.maloncy@hhs.nl \\ 3. Docente, Universidade Federal de São João Del Rei, Curso de Graduação em Engenharia Química; \\ marcelobatista@ufsj.edu.br
}

Recebido em: 28/05/2014 - Aprovado em: 17/09/2014 - Disponibilizado em: 15/12/2014

\begin{abstract}
RESUMO: Neste trabalho, a casca de arroz, resíduo da agroindústria brasileira, foi caracterizada e transformada em bioóleo através do processo de pirólise rápida, utilizando um reator batelada. Foram avaliados os efeitos da temperatura e da granulometria da casca arroz no rendimento em produtos líquido, sólido e gasoso. As fases orgânica e aquosa do bio-óleo bruto foram separadas por extração e caracterizadas. Os resultados mostraram que a $130{ }^{\circ} \mathrm{C}$, o tempo de secagem de 90 min foi suficiente para remover a umidade da casca de arroz. A análise granulométrica mostrou que o tamanho predominante da casca de arroz está na faixa de $1,4<\Phi<3,3 \mathrm{~mm}$. Foi observado que granulometrias menores aumentam o rendimento em líquido. O máximo rendimento em líquido (bio-óleo+água) foi de aproximadamente $40 \%$, obtido na temperatura de $575^{\circ} \mathrm{C}$. O bio-óleo bruto foi separado em frações aquosa $(\sim 17 \%)$ e orgânica $(\sim 83 \%)$ e, a acidez observada na fração aquosa sugere que a extração aumenta a alcalinidade do bio-óleo.
\end{abstract}

PALAVRAS-CHAVE. Bio-óleo. Casca de Arroz. Pirólise Rápida. Temperatura. Granulometria.

ABSTRACT: In this work, rice husk, an agricultural waste in Brazil, was characterized and converted into bio-oil via fast pyrolysis process (high heating rates in an inert atmosphere) carried out on a batch reactor. The effects of temperature and particle size of rice husk were evaluated on the yield of liquid, solid and gaseous products. The organic and aqueous phases of the brute bio-oil were separated by liquid-liquid extraction. The results showed that at $130{ }^{\circ} \mathrm{C}$, the drying time of 90 min was enough to remove the moisture from rice husk. The particle size analysis showed that the predominant size of rice husk is in the range of $1,4<\Phi<3,3 \mathrm{~mm}$. It was observed that smaller particle size affect positively on the liquid yield. The maximum liquid yield (bio-oil + water) was approximately $40 \%$, obtained at the temperature of $575{ }^{\circ} \mathrm{C}$. The brute bio-oil was separated in an aqueous fraction $(\sim 17 \%)$ and organic fraction $(\sim 83 \%)$ and, the acidity seem on the aqueous fraction suggests the raise on $\mathrm{pH}$ when the extraction is carried out.

KEYWORDS. Bio-oil. Rice Husk. Fast Pyrolysis. Temperature. Particle Size.

\section{INTRODUÇÃO}

Os combustíveis derivados de biomassa podem ser produzidos a curto prazo e, em geral, são menos danosos ao meio ambiente. Os biocombustíveis de primeira geração (bio- etanol e biodiesel) foram implementados em diferentes partes do mundo, no entanto, o bioetanol é produzido a partir da fermentação de açúcar ou amido e o biodiesel é produzido a partir de gorduras, que dependem da biomassa de alimentos. Por essa razão, novas pesquisas 
se concentram no desenvolvimento de biocombustíveis de segunda geração, que podem ser produzidos a partir de outras fontes de biomassa, como resíduos agrícolas, madeira, etc (VALLE et al., 2010).

A biomassa é um dos muitos grupos de resíduos sólidos gerados principalmente na agricultura, silvicultura, alimentação e fabricação de papel. Este material tem um potencial muito grande como substituinte do petróleo e do carvão mineral nos seus vários modos de uso ambientalmente sustentável, seja como combustível, fonte de insumos químicos, materiais carbonáceos, etc (FAAIJ et al., 2005). A biomassa é considerada como a maior fonte renovável de energia e o seu uso como fonte alternativa de carbono é muito importante para um país como o Brasil que possui grandes extensões de terras cultiváveis e clima favorável para a sua produção.

A tecnologia de pirólise rápida de biomassa é um método econômico e vantajoso de obter combustível líquido a pressão atmosférica, podendo transformar biomassa em bio-óleo continuamente em grande escala. A transformação de biomassa em bio-óleo apresenta vantagens devido a economia ao utilizar o bio-óleo como plataforma química (menor custo de transporte para as plantas em larga escala) e a flexibilidade relacionada a alimentação de biomassa (PARK et al., 2010).
Este processo integrado pode ser realizado em uma biorrefinaria que apresenta vantagens no transporte, armazenamento, manipulação, flexibilidade na produção e na comercialização (BUTLER et al., 2011).

A pirólise rápida promove a decomposição térmica da biomassa na ausência de oxigênio e se caracteriza por altas taxas de temperaturas com baixo tempo de residência da fase gasosa, diminuindo as reações secundárias dos compostos orgânicos primários, o que aumenta a fração de bio-óleo bruto (SANTOS, 2011). O bio-óleo apresenta alta densidade energética e é considerado energia limpa com baixíssimo conteúdo de compostos de enxofre e nitrogênio (ROCHA et al., 2005).

Alguns resíduos industriais podem ser aproveitados como fonte de biomassa para a produção do bio-óleo, que além de agregar valor ao resíduo, contribui para minimizar os impactos ambientais (JAYASINGHE \& HAWBOLDT, 2012). Neste contexto, destacase a casca de arroz, que quando depositada a céu aberto pode contaminar solos, ar e rios. Este material não pode ser utilizado na produção de rações para animais devido às suas baixas propriedades nutritivas e elevado teor de sílica, tornando-se imprópria para o consumo (DINIZ, 2005). A queima descontrolada deste material leva a emissão de poluentes e a perda do aproveitamento energético. Sem outro 
destino, a casca de arroz é então descartada em áreas rurais, permanecendo inalterada durante anos uma vez que apresenta uma lenta biodegradação e alto teor fenólico (ALMEIDA, 2010). Por outro lado, a pirólise rápida da casca de arroz para obtenção de bio-óleo é uma rota tecnológica importante tanto para a produção de biocombustíveis como para o meio ambiente.

A casca de arroz é um resíduo agroindustrial decorrente do beneficiamento das indústrias arrozeiras. Segundo a Companhia Nacional de Abastecimento (CONAB), o Brasil produziu em média 11.924.200 toneladas de arroz para a safra 2012/13 em seu levantamento de junho/2013, do qual, estima-se que mais de $20 \%$ seja resíduo (casca de arroz).

Diante do exposto, o presente trabalho tem como objetivo contribuir para o estudo da produção de bio-óleo, a partir da casca de arroz, em escala laboratorial, utilizando o processo de pirólise rápida em reator batelada e avaliar as propriedades das fases orgânica e aquosa provenientes da separação das frações do bio-óleo produzido. Nesse estudo, avaliouse a influência da temperatura de pirólise e da granulometria da casca de arroz no processo de produção de bio-óleo.

\section{METODOLOGIA}

Caracterização da casca de arroz

A casca de arroz utilizada nos experimentos foi adquirida na Empresa CODIL ALIMENTOS Ltda, localizada na cidade de Divinópolis-MG. A casca foi secada em estufa à temperatura de $130^{\circ} \mathrm{C}$. Um estudo preliminar para analisar a perda de massa da amostra foi realizado para obter o tempo de secagem. Neste estudo a amostra foi retirada da estufa e pesada a cada 30 min. A porcentagem de massa perdida foi calculada pela equação 1 .

$$
\text { Perda de massa }(\%)=100-\frac{m_{f} x 100}{m_{i}}(1)
$$

onde: $\mathrm{m}_{\mathrm{f}}$ é a massa final pesada e, $\mathrm{m}_{\mathrm{i}}$ a massa inicial da amostra antes da secagem. A retirada da maior quantidade de água da casca de arroz é importante para diminuir a quantidade de água no produto, aumentando o rendimento em bio-óleo. Em seguida, com o auxílio de uma peneira vibratória, durante $10 \mathrm{~min}$, a casca foi separada nas seguintes granulometrias: $0,150 \mathrm{~mm}<\Phi, \quad 0,150<\Phi<0,300 \mathrm{~mm}$, $0,300<\Phi<0,500 \mathrm{~mm}, \quad 0,500<\Phi<1,400 \mathrm{~mm}$, $1,400<\Phi<3,350 \mathrm{~mm}$ e $\Phi>3,350 \mathrm{~mm}$. A massa retida em cada peneira e no fundo foi pesada, encontrando-se, portanto, a granulometria predominante da amostra de casca de arroz. 
Pirólise

A pirólise rápida da casca de arroz foi realizada em um reator de aço inox de $280 \mathrm{~mL}$, pressão atmosférica. O aquecimento ( 100 ${ }^{\circ} \mathrm{C} / \mathrm{min}$ ) foi efetuado com o auxílio de uma resistência de 2.000 Watts, feita sob medida para o reator de aço. Para melhor isolamento térmico, o reator foi envolto com lã de rocha. A temperatura foi medida por um controlador ligado a um termopar. Em cada batelada utilizou-se aproximadamente $30 \mathrm{~g}$ de casca de arroz seca. Foi utilizado nitrogênio como gás de arraste inerte, com fluxo de aproximadamente $50 \mathrm{~mL} / \mathrm{min}$, durante todo o processo. $O$ tempo de residência na temperatura final de pirólise foi de 2 a $3 \mathrm{~min}$ para cada experimento. $\mathrm{Na}$ saída do reator, o produto líquido (óleo + água) foi condensado em tubos de ensaio imersos em banho de gelo.

Separação das frações do bio-óleo

As amostras de bio-óleo foram separadas por extração líquido-líquido com a adição de $4 \mathrm{~mL}$ de diclorometano, repetição por 4 vezes da extração e posterior evaporação do diclorometano. Para quantificação, foi realizado medidas de massas antes e após a extração e, as frações aquosas tiveram o pH aferido com um pHmetro.

\section{RESULTADOS E DISCUSSÃO}

A Tabela 1 mostra os resultados das perdas de massa durante a secagem das amostras (AM01 e AM02) de casca de arroz.

Tabela 1 - Perda de massa durante a secagem da casca de arroz.

\begin{tabular}{ccccc}
\hline $\begin{array}{c}\text { Tempo } \\
(\mathbf{m i n})\end{array}$ & $\begin{array}{c}\text { AM01 } \\
(\mathbf{g})\end{array}$ & $\begin{array}{c}\text { \% perda } \\
\text { AM01* }\end{array}$ & $\begin{array}{c}\text { AM02 } \\
(\mathbf{g})\end{array}$ & $\begin{array}{c}\text { \% perda } \\
\text { AM02* }\end{array}$ \\
\hline $\mathbf{0}$ & 132,10 & --- & 125,19 & --- \\
$\mathbf{6 0}$ & 119,69 & 9,39 & 112,43 & 10,19 \\
$\mathbf{9 0}$ & 118,97 & 9,94 & 112,25 & 10,34 \\
$\mathbf{1 2 0}$ & 118,95 & 9,95 & 112,21 & 10,37 \\
\hline$*$
\end{tabular}

* percentual de perda de massa

Na Tabela 1 pode-se observar que após 90 min de secagem não houve mais perda significativa de massa, uma vez que a porcentagem de massa perdida em ambas as amostras mantém-se praticamente inalterada. Esses resultados indicam, portanto, que toda a umidade presente na casca de arroz é retirada em cerca de 90 min de secagem em estufa. Comparando as amostras 1 e 2 é possível observar que a porcentagem de perda de massa em ambas é muito próxima, o que está dentro do esperado, uma vez que a matéria prima utilizada é a mesma e de mesma procedência.

Após a secagem realizou-se a análise granulométrica da casca de arroz e os resultados estão apresentados na Tabela 2. 
Tabela 2 - Influência do tamanho de partícula no rendimento em gás, líquido e sólido.

\begin{tabular}{ccc}
\hline Peneira & $\begin{array}{c}\text { Faixa } \\
\text { granulométrica } \\
(\mathbf{m m})\end{array}$ & $\begin{array}{c}\text { Percentual } \\
(\% \mathrm{~m} / \mathrm{m})\end{array}$ \\
\hline $\mathbf{1}$ & $0,150<\Phi$ & $0,46 \%$ \\
$\mathbf{2}$ & $0,150<\Phi<0,300$ & $0,82 \%$ \\
$\mathbf{3}$ & $0,300<\Phi<0,500$ & $2,30 \%$ \\
$\mathbf{4}$ & $0,500<\Phi<1,400$ & $27,81 \%$ \\
$\mathbf{5}$ & $1,400<\Phi<3,350$ & $68,32 \%$ \\
$\mathbf{6}$ & $\Phi>3,350$ & $0,28 \%$ \\
\hline
\end{tabular}

Na Tabela 2 é possível observar que, na peneira 5, reteve-se a maior porcentagem em massa de casca de arroz. Desta maneira pode-se afirmar que a granulometria predominante da casca de arroz está entre $1,400<\Phi<3,350 \mathrm{~mm}$. Entretanto, na peneira 4, também reteve-se quantidade significativa de casca e, devido ao menor tamanho de partícula retido, $0,500<\Phi<1,400$, este intervalo granulométrico foi utilizado na avaliação da temperatura para produção de bio-óleo.

$\mathrm{Na}$ Figura 1 são apresentados os rendimentos em produtos líquido, gasoso e sólido do processo de pirólise rápida em diferentes temperaturas. Todos os experimentos foram realizados com tempo de residência na temperatura final de pirólise entre 2 e $3 \mathrm{~min}$, granulometria $0,500<\Phi<1,400 \mathrm{~mm}$, taxa de aquecimento $\sim 100{ }^{\circ} \mathrm{C} / \mathrm{min}$, em batelada, sob atmosfera de nitrogênio.

Figura 1 - Rendimento do produto líquido (óleo+água), gasoso e sólido em diferentes temperaturas de pirólise: com tempo de residência de 2-3 min, granulometria $0,500<\Phi<1,400 \mathrm{~mm}$.

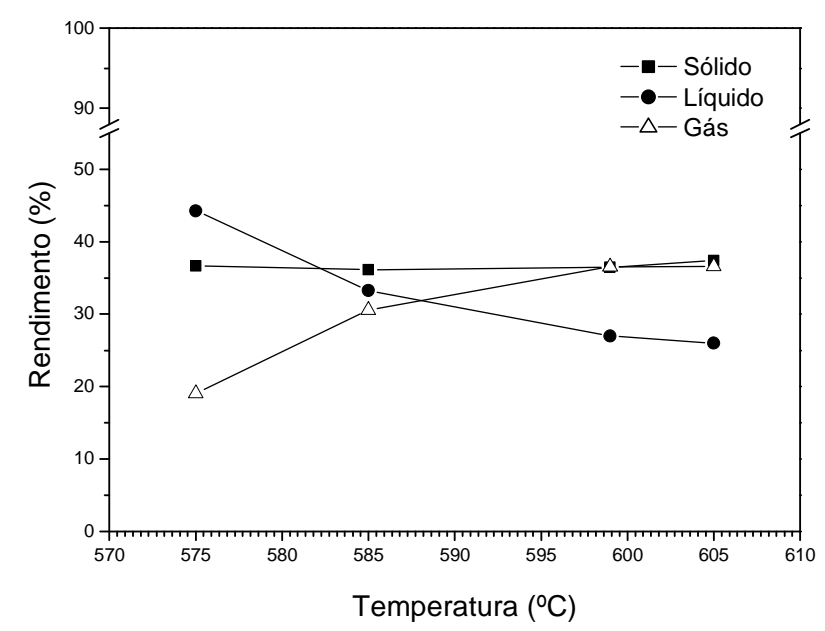

Na Figura 1 é possível observar que o rendimento em líquido foi máximo na temperatura final de pirólise de $575{ }^{\circ} \mathrm{C}$ e decresceu com o aumento da temperatura. Por outro lado, se observa que o rendimento do produto gasoso aumenta com o aumento da temperatura de pirólise, tendo seu mínimo na mesma temperatura onde ocorre o rendimento máximo em líquido. Esse maior rendimento do produto gasoso, em temperaturas mais elevadas de pirólise, pode ser atribuído ao craqueamento secundário dos vapores e do carvão em gás (HEO et al., 2010). 
Conforme mostrado na Figura 1, no tempo de permanência de 2 a 3 min e temperatura de $575{ }^{\circ} \mathrm{C}$ observa-se o maior rendimento em líquido. É importante ressaltar que, em tempos longos de permanência, ocorre diminuição do rendimento em óleo provavelmente devido à gaseificação e/ou craqueamento térmico dos produtos da pirólise (TSAI et al., 2007). Além disso, em temperaturas em torno de $500{ }^{\circ} \mathrm{C}$ ocorre queima incompleta da biomassa, reduzindo-se a quantidade de bio-óleo (ALMEIDA, 2010). Desta maneira, justifica-se a utilização de temperaturas acima de $500{ }^{\circ} \mathrm{C}$ e tempos de permanência relativamente curtos para obter-se uma produção máxima de bio-óleo por pirólise rápida.

Analisando os resultados obtidos na Figura 1 é possível observar também que, em temperaturas superiores à $600{ }^{\circ} \mathrm{C}$, o rendimento em gás torna-se praticamente constante e o rendimento em líquido apresenta apenas um suave decaimento $(0,99 \%)$. Observa-se também que, acima de $600{ }^{\circ} \mathrm{C}$, o rendimento em produto sólido (cinzas) apresenta um aumento suave $(0,92 \%)$, o qual está diretamente relacionado com o leve decaimento no rendimento do produto líquido. Com isso, observa-se que o suave aumento de sólidos interferiu na produção do bio-óleo bruto, uma vez que em temperaturas acima de $600{ }^{\circ} \mathrm{C}$ há também formação de produto sólido.

Na Figura 1, nota-se que, em geral, o rendimento de produto sólido permanece praticamente constante. Os resultados indicam a ocorrência de gaseificação com o aumento da temperatura e, consequentemente, a redução do rendimento em produto líquido.

Na Tabela 3 estão apresentados os resultados dos testes de pirólise rápida da casca de arroz usando diferentes granulometria. Como se pode observar, a produção de sólido mantém-se praticamente estável em ambas as granulometrias, assim como ocorreu no estudo da influência da temperatura.

Tabela 3 - Influência do tamanho de partícula no rendimento em gás, líquido e sólido.

\begin{tabular}{ccccc}
\hline $\begin{array}{c}\text { Tamanho } \\
\boldsymbol{\Phi}(\mathbf{m m})\end{array}$ & $\begin{array}{c}\text { Temp. } \\
\left({ }^{\mathbf{}} \mathbf{C}\right)\end{array}$ & $\begin{array}{c}\text { Sólido } \\
(\boldsymbol{\%})\end{array}$ & $\begin{array}{c}\text { Líquido } \\
(\boldsymbol{\%})\end{array}$ & $\begin{array}{c}\text { Gasoso } \\
(\boldsymbol{\%})\end{array}$ \\
\hline $0,500 \leq \Phi$ & 550 & 34,63 & 28,83 & 36,53 \\
$1,4 \leq \Phi \leq 3,35$ & 544 & 34,54 & 25,40 & 40,05 \\
\hline
\end{tabular}

Na Tabela 3, nota-se que na menor granulometria $(0,500 \mathrm{~mm} \leq \Phi)$ obteve-se o maior rendimento em líquido e menor rendimento em gás. Este resultado era esperado uma vez que, ao diminuir o tamanho de partícula, permite-se que a transferência de calor seja mais uniforme e favoreça a pirólise da casca de arroz (ALMEIDA, 2010). 
Foi observado que todo o óleo foi extraído do bio-óleo bruto após utilizar diclorometano quatro vezes. Na Tabela 4 são apresentados os percentuais das frações orgânicas e aquosas e o $\mathrm{pH}$ da fase aquosa, após a extração líquido-líquido.

Tabela 4 - Características das frações orgânica e aquosa.

\begin{tabular}{ccccc}
\hline Amostra & $\begin{array}{c}\text { Temp. } \\
\left({ }^{\mathbf{}} \mathbf{C}\right)\end{array}$ & $\begin{array}{c}\text { Fração } \\
\text { orgânica } \\
(\%)\end{array}$ & $\begin{array}{c}\text { Fração } \\
\text { aquosa } \\
(\%)\end{array}$ & $\begin{array}{c}\mathbf{p H} \\
\text { fração } \\
\text { aquosa }\end{array}$ \\
\hline $0,500<\Phi<$ & 575 & 83,13 & 16,87 & 3,14 \\
$1,400 \mathrm{~mm}$ & & & & \\
$\begin{array}{c}0,500<\Phi< \\
1,400 \mathrm{~mm}\end{array}$ & 585 & 82,65 & 17,35 & 3,04 \\
\hline
\end{tabular}

Os resultados da Tabela 4 mostram que, em temperaturas próximas, os valores percentuais das frações aquosa $(\sim 17 \%)$ e orgânica $(\sim 83 \%)$ das amostras são muito próximos, bem como os valores de $\mathrm{pH}$. A acidez observada nas frações aquosas sugere que a extração aumenta significativamente a alcalinidade do bio-óleo, uma vez que os ácidos produzidos permanecem solúveis na fração aquosa com pH ácido (GOMES, 2010). Isto justifica a acidez da fração aquosa observada para as amostras.

\section{CONCLUSÃO}

Diante dos resultados apresentados e nas condições experimentais utilizadas pode-se concluir que o tempo de $90 \mathrm{~min}$ é suficiente para a secagem da casca bruta a $130{ }^{\circ} \mathrm{C} . \mathrm{Na}$ pirólise rápida da casca de arroz em reator batelada, a temperatura e a granulometria da casca influenciam no rendimento de produtos líquidos e gasosos. O maior rendimento em produtos líquidos (óleo + água) foi de aproximadamente $40 \%$, na temperatura de 575 ${ }^{\circ} \mathrm{C}$. Os resultados mostraram, também, que na menor granulometria estudada obtém-se o maior rendimento em produto líquido $(\sim 30 \%)$. Em contraste, o rendimento em sólido (carvão) parece não ser afetado pela temperatura de pirólise tampouco pela granulometria da partícula de casca de arroz. O bio-óleo bruto foi separado em frações aquosa ( 17\%) e orgânica $(\sim 83 \%)$ e, a acidez observada na fração aquosa sugere que a extração aumenta a alcalinidade do bio-óleo.

\section{AGRADECIMENTOS}

Camila Oliveira Guimarães e Gabriel Renault de Mendonça agradecem à FAPEMIG pela bolsa de Iniciação Científica. Ao apoio financeiro do projeto CAPES/BRANETEC 009/2012. 


\section{REFERÊNCIAS BIBLIOGRÁFICAS}

ALMEIDA, S. R. Pirólise rápida de casca de arroz: Estudo de parâmetros e caracterização de produtos. 2010, 74 p. Dissertação.

BUTLER, E.; DEVLIN, G. MEIER, D.;

MCDONNELL, K. Renewable and Sustainable Energy Reviews, 2011, 15, 4171.

DINIZ, J. Conversão térmica de casca de arroz à baixa temperatura: Produção de bio-óleo e resíduo sílico-carbonoso adsorvente. 2005, 156 p. Tese.

FAAIJ, A.; WALTER, A.; BAUEN, A.; BEZZON, G.; ROCHA, J. D.; MOREIRA, J. R. CRAIG, K. R.; OVEREND, R. P.; BAIN, R. L. Novas Tecnologias para os Vetores Modernos de Energia de Biomassa. In: ROSILLE-CALLE, F.; BAJAY, S. V.; ROTHMAN, H. Uso da biomassa para produção de energia na indústria brasileira. Campinas: Editora da UNICAMP, 2005, p.339411.

GOMES, M. S. Produção de bio-óleo através do processo termoquímico de pirólise. 2010, 34 p. Trabalho de graduação.

H. S. HEO; H. J. PARK; J.I. DONG; S. H. PARK; S. KIM; D. J. SUH; Y.W. SUH; S. S.
KIM; Y.K PARK. Journal of Industrial and Engineering Chemistry. 2010, 16, 27.

JAYASINGHE, P.; HAWBOLDT, K. Renewable and Sustainable Energy Reviews. 2012, 16, 798.

PARK, H. J.; HEO, H. S.; PARK, Y. K.; YIM, J. H.; JEON J. K.; PARK, J.; RYU, C.; KIM, S. S. Bioresource Technology, 2010, 101, S83.

ROCHA, J. D.; PÉREZ, J. M. M.; GÓMEZ, E. R.; CORTEZ, L. A. B. Tecnologia transforma resíduos em novos negócios: Bio-óleo obtido por pirólise rápida de palha e bagaço como fonte de combustível e produtos químicos. ALCOOLbrás, , 2005, 95, 88.

SANTOS, K. G. Aspectos fundamentais da pirólise de biomassa em leito de jorro: Fluidodinâmica e cinética do processo. 2011, 235 p. Tese.

VALLE, B.; GAYUBO, A. G.; ALONSO, A.; AGUAYO, A. T.; BILBAO, J. Applied

Catalysis B: Environmental, 2010, 100, 318.

TSAI, W. T.; LEE, M. K.; CHANG, Y.M.

Bioresource Technology. 2007, 98, 22. 